The Journal of Nonlinear $\mathbf{S}$ cience and Applications http://www.tjnsa.com

\title{
GENERALIZED CONE METRIC SPACES
}

\author{
ISMAT BEG, MUJAHID ABBAS AND TALAT NAZIR
}

\begin{abstract}
A notion of generalized cone metric space is introduced, and some convergence properties of sequences are proved. Also some fixed point results for mappings satisfying certain contractive conditions are obtained. Our results complement, extend and unify several well known results in the literature.
\end{abstract}

\section{INTRODUCTION}

To overcome fundamental flaws in Dhage's theory of generalized metric spaces [3], Mustafa and Sims [8] introduced a more appropriate generalization of metric spaces, that of $G$-metric spaces. Afterwards, Mustafa et. el [6] obtained several fixed point theorems for mappings satisfying different contractive conditions in $G$-metric spaces. Recently Guang and Xian [4] defined the concept of a cone metric space, replacing the set of real numbers by an ordered Banach space and obtained some fixed point theorems for mappings satisfying different contractive conditions. The normality property of cone was an important ingredient in their results (see also, [1], and [2]). Afterward Rezapour and Hamlbarani [9] omitting the assumption of normality of cone generalized some results of [4]. In this paper, a concept of $G$-cone metric space is introduced by replacing the set of real numbers by an ordered Banach space, and convergence properties of sequences are proved. Finally some fixed point theorems satisfying certain contractive conditions are obtained. It is worth mentioning that we did not use the normality property of cone to obtain results in this paper. Our results have several consequences including generalizations of comparable results in the literature (see for example [4, 5, 6, 9] and the references therein).

Date: Received: November 18, 2009 .

2000 Mathematics Subject Classification. Primary 47H10; Secondary 46B20; 54H25; 54E35.

Key words and phrases. Generalized cone metric space; contractive mappings; fixed point. 


\section{Generalized COne metric spaces}

First we define generalized cone metric space and prove some convergence properties of sequences.

Let $E$ be a real Banach space. A subset $P$ of $E$ is called a cone if and only if:

(a) $P$ is closed, non empty and $P \neq\{0\}$,

(b) $a, b \in R, a, b \geq 0, x, y \in P$ implies $a x+b y \in P$; More generally if $a, b$, $c \in R, a, b, c \geq 0, x, y, z \in P \Rightarrow a x+b y+c z \in P$,

(c) $P \cap(-P)=\{0\}$.

Given a cone $P \subset E$, we define a partial ordering $\leq$ with respect to $P$ by $x \leq y$ if and only if $y-x \in P$. A cone $P$ is called normal if there is a number $K>0$ such that for all $x, y \in E$,

$$
0 \leq x \leq y \text { implies }\|x\| \leq K\|y\| .
$$

The least positive number satisfying the above inequality is called the normal constant of $P$, while $x \ll y$ stands for $y-x \in$ int $P$ (interior of $P$ ).

Rezapour and Hamlbarani [9] proved that there are no normal cones with normal constants $K<1$ and for each $k>1$ there are cones with normal constants $K>k$.

Definition 2.1. Let $X$ be a nonempty set. Suppose a mapping $G: X \times X \times X \rightarrow$ $E$ satisfies:

$\left(\mathrm{G}_{1}\right) G(x, y, z)=0$ if $x=y=z$,

$\left(\mathrm{G}_{2}\right) 0<G(x, x, y)$; whenever $x \neq y$, for all $x, y \in X$,

$\left(\mathrm{G}_{3}\right) G(x, x, y) \leq G(x, y, z)$; whenever $y \neq z$,

$\left(\mathrm{G}_{4}\right) G(x, y, z)=G(x, z, y)=G(y, x, z)=\ldots$ (Symmetric in all three variables),

$\left(\mathrm{G}_{5}\right) G(x, y, z) \leq G(x, a, a)+G(a, y, z)$ for all $x, y, z, a \in X$.

Then $G$ is called a generalized cone metric on $X$, and $X$ is called a generalized cone metric space or more specifically a $G$ - cone metric space.

The concept of a $G$ - cone metric space is more general than that of a $G-$ metric spaces and cone metric spaces. For the definition of $G$ - metric, cone metric spaces and related concepts we refer the reader to [4, 7, 8, 9].

Definition 2.2. A $G$ - cone metric space $X$ is symmetric if

$$
G(x, y, y)=G(y, x, x) \text { for all } x, y \in X .
$$

Following are examples of symmetric and non symmetric $G$-cone metric spaces respectively.

Example 2.3. Let $(X, d)$ be a cone metric space. Define $G: X \times X \times X \rightarrow E$, by $G(x, y, z)=d(x, y)+d(y, z)+d(z, x)$.

Example 2.4. Let $X=\{a, b\}, E=R^{3}, P=\{(x, y, z) \in E \mid x, y, z \geq 0\}$. Define $G: X \times X \times X \rightarrow E$ by

$$
\begin{aligned}
G(a, a, a) & =(0,0,0)=G(b, b, b), \\
G(a, b, b) & =(0,1,1)=G(b, a, b)=G(b, b, a), \\
G(b, a, a) & =(0,1,0)=G(a, b, a)=G(a, a, b)
\end{aligned}
$$

Note that $X$ is nonsymmetric $G$-cone metric space as $G(a, a, b) \neq G(a, b, b)$. 
Remark 2.5. If $E$ is a real Banach space with cone $P$ and if $a \leq \lambda a$ where $a \in P$ and $0<\lambda<1$ then $a=0$.

Proposition 2.6. Let $X$ be a $G$ - cone metric space, define $d_{G}: X \times X \rightarrow E$ by

$$
d_{G}(x, y)=G(x, y, y)+G(y, x, x) .
$$

Then $\left(X, d_{G}\right)$ is a cone metric space.

It can be noted that $G(x, y, y) \leq \frac{2}{3} d_{G}(x, y)$. If $X$ is a symmetric $G$ - cone metric space, then

for all $x, y \in X$.

$$
d_{G}(x, y)=2 G(x, y, y)
$$

Definition 2.7. Let $X$ be a $G$ - cone metric space and $\left\{x_{n}\right\}$ be a sequence in X. We say that $\left\{x_{n}\right\}$ is:

(a) Cauchy sequence if for every $c \in E$ with $0 \ll c$, there is $N$ such that for all $n, m, l>N, G\left(x_{n}, x_{m}, x_{l}\right) \ll c$.

(b) Convergent sequence if for every $c$ in $E$ with $0 \ll c$, there is $N$ such that for all $m, n>N, G\left(x_{m}, x_{n}, x\right) \ll c$ for some fixed $x$ in $X$. Here $x$ is called the limit of a sequence $\left\{x_{n}\right\}$ and is denoted by $\lim _{n \rightarrow \infty} x_{n}=x$ or $x_{n} \rightarrow x$ as $n \rightarrow \infty$.

A $G$ - cone metric space $X$ is said to be complete if every Cauchy sequence in $X$ is convergent in $X$.

Proposition 2.8. Let $X$ be a $G$-cone metric space then the following are equivalent.

(i) $\left\{x_{n}\right\}$ is converges to $x$.

(ii) $G\left(x_{n}, x_{n}, x\right) \rightarrow 0$, as $n \rightarrow \infty$.

(iii) $G\left(x_{n}, x, x\right) \rightarrow 0$, as $n \rightarrow \infty$.

(iv) $G\left(x_{m}, x_{n}, x\right) \rightarrow 0$, as $m, n \rightarrow \infty$.

Lemma 2.9. Let $X$ be a $G$ - cone metric space, $\left\{x_{m}\right\},\left\{y_{n}\right\}$, and $\left\{z_{l}\right\}$ be sequences in $X$ such that $x_{m} \rightarrow x, y_{n} \rightarrow y$, and $z_{l} \rightarrow z$, then $G\left(x_{m}, y_{n}, z_{l}\right) \rightarrow$ $G(x, y, z)$ as $m, n, l \rightarrow \infty$.

Proof. Given that $\left\{x_{m}\right\},\left\{y_{n}\right\},\left\{z_{l}\right\}$ converges to $x, y, z$ respectively. For any $c \in E$ with $0 \ll c$, we can find $N$ such that for all $m, n, l>N$, we have

$$
\begin{aligned}
G\left(x_{m}, x, x\right) & \ll c / 3, G\left(y_{n}, y, y\right) \ll c / 3 \\
\text { and } G\left(z_{l}, z, z\right) & \ll c / 3 .
\end{aligned}
$$

Since

and

$$
\begin{aligned}
G\left(x_{m}, y_{n}, z_{l}\right) & \leq G\left(x_{m}, x, x\right)+G\left(x, y_{n}, z_{l}\right), \\
G\left(x, y_{n}, z_{l}\right) & \leq G\left(y_{n}, y, y\right)+G\left(y, x, z_{l}\right),
\end{aligned}
$$

Therefore

$$
G\left(y, x, z_{l}\right) \leq G\left(z_{l}, z, z\right)+G(z, y, x) .
$$

$$
\begin{aligned}
& G\left(x_{m}, y_{n}, z_{l}\right) \\
\leq & G\left(x_{m}, x, x\right)+G\left(y_{n}, y, y\right)+G\left(z_{l}, z, z\right)+G(z, y, x) .
\end{aligned}
$$


Thus

$$
\begin{aligned}
& G\left(x_{m}, y_{n}, z_{l}\right)-G(x, y, z) \\
\leq & G\left(x_{m}, x, x\right)+G\left(y_{n}, y, y\right)+G\left(z_{l}, z, z\right) \\
\ll & \frac{c}{3}+\frac{c}{3}+\frac{c}{3}=c .
\end{aligned}
$$

Thus

$$
G\left(x_{m}, y_{n}, z_{l}\right)-G(x, y, z) \ll c .
$$

Similarly

$$
G(x, y, z)-G\left(x_{m}, y_{n}, z_{l}\right) \ll c .
$$

Thus for all $k \geq 1$, we have

and

$$
G\left(x_{m}, y_{n}, z_{l}\right)-G(x, y, z) \ll \frac{c}{k},
$$

$$
G(x, y, z)-G\left(x_{m}, y_{n}, z_{l}\right) \ll \frac{c}{k} .
$$

It implies that $\frac{c}{k}-\left(G(x, y, z)-G\left(x_{m}, y_{n}, z_{l}\right)\right)$ and $\frac{c}{k}+\left(G\left(x_{m}, y_{n}, z_{l}\right)-G(x, y, z)\right.$ are in $P$. Since $P$ is closed and $\frac{c}{k} \rightarrow 0$ as $k \rightarrow \infty$, therefore $\lim _{m, n, l \rightarrow \infty} G\left(x_{m}, y_{n}, z_{l}\right)-$ $G(x, y, z)$ and $G(x, y, z)-\lim _{m, n, l \rightarrow \infty} G\left(x_{m}, y_{n}, z_{l}\right) \in P$. It gives that

$$
\lim _{m, n, l \rightarrow \infty} G\left(x_{m}, y_{n}, z_{l}\right)=G(x, y, z) .
$$

Hence the result follows.

Lemma 2.10. Let $\left\{x_{n}\right\}$ be a sequence in $G-$ cone metric space $X$ and $x \in X$. If $\left\{x_{n}\right\}$ converges to $x$, and $\left\{x_{n}\right\}$ converges to $y$, then $x=y$.

Proof. For any $c \in E$, with $0 \ll c$, there is $N$ such that for all $m, n>N$,

Now

$$
G\left(x_{m}, x_{n}, x\right) \ll \frac{c}{3} \text { and } G\left(x_{m}, x_{n}, y\right) \ll \frac{c}{3} .
$$

and

$$
G(x, x, y) \leq G\left(x_{m}, x_{n}, y\right)+G\left(x_{m}, x_{n}, x\right)
$$

Hence

$$
G\left(x_{n}, x, y\right) \leq G\left(x_{m}, x_{m}, y\right)+G\left(x_{m}, x_{n}, x\right)
$$

$$
\begin{aligned}
G(x, x, y) & \leq G\left(x_{n}, x_{n}, x\right)+G\left(x_{m}, x_{n}, y\right)+G\left(x_{m}, x_{n}, x\right) \\
& \ll \frac{c}{3}+\frac{c}{3}+\frac{c}{3}=c .
\end{aligned}
$$

Thus $G(x, x, y) \ll \frac{c}{m}$ for all $m \geq 1$. So $\frac{c}{m}-G(x, x, y) \in P$, for all $m \geq 1$. Since $\frac{c}{m} \rightarrow 0$, as $m \rightarrow \infty$ and $P$ is closed, therefore $-G(x, x, y) \in P$ but $G(x, x, y) \in P \Rightarrow G(x, x, y)=0$. Therefore $x=y$.

Lemma 2.11. Let $\left\{x_{n}\right\}$ be a sequence in a $G$ - cone metric space $X$ and if $\left\{x_{n}\right\}$ converges to $x$ for $x \in X$, then $G\left(x_{m}, x_{n}, x\right) \rightarrow 0$ as $m, n \rightarrow \infty$. 
Proof. Suppose that $\left\{x_{n}\right\}$ converges to $x$. Then there is $N$, such that when $m$, $n>N$, we have

$$
G\left(x_{n}, x_{m}, x\right) \ll c .
$$

Thus for all $k \geq 1$, we have

$$
G\left(x_{n}, x_{m}, x\right) \ll \frac{c}{k},
$$

It implies that $\frac{c}{k}-G\left(x_{n}, x_{m}, x\right) \in P$ and hence

$$
-\lim _{n, m \rightarrow \infty} G\left(x_{n}, x_{m}, x\right) \in P \text {. }
$$

But $\lim _{n, m \rightarrow \infty} G\left(x_{n}, x_{m}, x\right) \in P$. This means $\lim _{n, m \rightarrow \infty} G\left(x_{n}, x_{m}, x\right)=0$.

Lemma 2.12. Let $\left\{x_{n}\right\}$ be a sequence in a $G$ - cone metric space $X$ and $x \in X$. If $\left\{x_{n}\right\}$ converges to $x \in X$, then $\left\{x_{n}\right\}$ is a Cauchy sequence.

Proof. For any $c \in E$ with $0 \ll c$. From $x_{n} \rightarrow x$, there is $N$ such that for all $m, n, l>N$, we have

$$
\begin{aligned}
G\left(x_{m}, x_{n}, x\right) & \ll c / 3, G\left(x_{n}, x_{l}, x\right) \ll c / 3 \\
\text { and } G\left(x_{m}, x_{l}, x\right) & \ll c / 3 .
\end{aligned}
$$

Now

$$
\begin{aligned}
G\left(x_{m}, x_{n}, x_{l}\right) & \leq G\left(x_{m}, x_{n}, x\right)+G\left(x_{n}, x_{l}, x\right)+G\left(x_{m}, x_{l}, x\right) \\
& \ll c .
\end{aligned}
$$

Therefore $\left\{x_{n}\right\}$ is a Cauchy sequence.

Lemma 2.13. Let $\left\{x_{n}\right\}$ be a sequence in a $G$ - cone metric space $X$ and if $\left\{x_{n}\right\}$ is a Cauchy sequence in $X$, then $G\left(x_{m}, x_{n}, x_{l}\right) \rightarrow 0$, as $m, n, l \rightarrow \infty$.

Proof. Suppose that $\left\{x_{n}\right\}$ is a Cauchy sequence. Then for every $c \in E$ with $0 \ll c$, there is $N$ such that for all $m, n, l>N, G\left(x_{m}, x_{n}, x_{l}\right) \ll c$. Thus for all $k$ $\geq 1$, we have

$$
G\left(x_{n}, x_{m}, x_{l}\right) \ll \frac{c}{k} .
$$

It implies that $\frac{c}{k}-G\left(x_{n}, x_{m}, x_{l}\right) \in P$ and hence

$$
-\lim _{n, m, l \rightarrow \infty} G\left(x_{n}, x_{m}, x_{l}\right) \in P .
$$

But $\lim _{n, m, l \rightarrow \infty} G\left(x_{n}, x_{m}, x_{l}\right) \in P$. This means $\lim _{n, m, l \rightarrow \infty} G\left(x_{n}, x_{m}, x_{l}\right)=0$.

\section{FiXED POINT THEOREMS}

In this section we prove fixed point theorems in the setting of $G$ - cone metric spaces.

Theorem 3.1. Let $X$ be a complete symmetric $G$ - cone metric space and $T$ : $X \rightarrow X$ be a mapping satisfying one of the following conditions

$$
\begin{aligned}
G(T x, T y, T z) \leq & a G(x, y, z)+b G(x, T x, T x) \\
& +c G(y, T y, T y)+d G(z, T z, T z),
\end{aligned}
$$


or

$$
\begin{aligned}
G(T x, T y, T z) \leq & a G(x, y, z)+b G(x, T x, x) \\
& +c G(y, y, T y)+d G(z, z, T z),
\end{aligned}
$$

for all $x, y, z \in X$, where $0 \leq a+b+c+d<1$. Then $T$ has a unique fixed point. Proof. Suppose that $T$ satisfies condition (1), then for all $x, y \in X$

$$
\begin{aligned}
& G(T x, T y, T y) \\
\leq & a G(x, y, y)+b G(x, T x, T x)+(c+d) G(y, T y, T y)
\end{aligned}
$$

and

$$
\begin{aligned}
& G(T y, T x, T x) \\
\leq & a G(y, x, x)+b G(y, T y, T y)+(c+d) G(x, T x, T x) .
\end{aligned}
$$

Since $X$ is a symmetric $G$ - cone metric space, therefore by adding (3) and (4), we have

$$
\begin{aligned}
& d_{G}(T x, T y) \\
\leq & a d_{G}(x, y)+\frac{b+c+d}{2} d_{G}(x, T x)+\frac{b+c+d}{2} d_{G}(y, T y) \\
= & \alpha d_{G}(x, y)+\beta d_{G}(x, T x)+\gamma d_{G}(y, T y),
\end{aligned}
$$

for all $x, y \in X$, where $\alpha=a, \beta=\gamma=\frac{b+c+d}{2}$. Obviously $\alpha+\beta+\gamma<1$. Take any point $x \in X$ and consider the sequence $\left\{T^{n} x\right\}$. Replacing $x$ by $T^{n} x$ and $y$ by $T^{n-1} x$ in (5), we obtain

$$
\begin{aligned}
& d_{G}\left(T^{n+1} x, T^{n} x\right) \\
\leq & \alpha d_{G}\left(T^{n} x, T^{n-1} x\right)+\beta d_{G}\left(T^{n} x, T^{n+1} x\right) \\
& +\gamma d_{G}\left(T^{n-1} x, T^{n} x\right) .
\end{aligned}
$$

It further implies that

$$
d_{G}\left(T^{n+1} x, T^{n} x\right) \leq p d_{G}\left(T^{n} x, T^{n-1} x\right),
$$

where $p=\frac{\alpha+\gamma}{1-\beta}<1$. It follows that

$$
d_{G}\left(T^{n+1} x, T^{n} x\right) \leq p^{n} d_{G}(T x, x) .
$$

For any $m>n$, we have

$$
d_{G}\left(T^{m} x, T^{n} x\right) \leq \frac{p^{n}}{1-p} d_{G}(T x, x) .
$$

Let $0 \ll c$ be given. Following similar arguments to those given in [9, theorem 2.3], we conclude that $\frac{p^{n}}{1-p} d_{G}(T x, x) \ll c$. So we have $d_{G}\left(T^{m} x, T^{n} x\right) \ll c$, for all $m>n$. Therefore $\left\{T^{n} x\right\}$ is a Cauchy sequence and hence $T^{n} x \rightarrow z$. 
Next we will show that $T z=z$. First, we prove that $T^{n+1} x \rightarrow T z$. For this, take $x=T^{n} x, y=z$ in $(5)$,

$$
\begin{aligned}
& d_{G}\left(T^{n+1} x, T z\right) \\
\leq \quad & \alpha d_{G}\left(T^{n} x, z\right)+\beta d_{G}\left(T^{n} x, T^{n+1} x\right)+\gamma d_{G}(T z, z) \\
\leq \quad & \alpha d_{G}\left(T^{n} x, z\right)+\beta d_{G}\left(T^{n} x, T^{n+1} x\right) \\
& +\gamma\left(d_{G}\left(T^{n+1} x, T z\right)+d_{G}\left(T^{n+1} x, z\right)\right) \\
\leq & \alpha d_{G}\left(T^{n} x, z\right)+\beta p^{n} d_{G}(T x, x) \\
& +\gamma\left(d_{G}\left(T^{n+1} x, T z\right)+d_{G}\left(T^{n+1} x, z\right)\right) .
\end{aligned}
$$

Thus

$$
\begin{aligned}
d_{G}\left(T^{n+1} x, T z\right) & \leq \frac{1}{1-\gamma}\left(\alpha d_{G}\left(T^{n} x, z\right)+\beta p^{n} d_{G}(T x, x)\right. \\
\left.+\gamma d_{G}\left(T^{n+1} x, z\right)\right) & \ll c
\end{aligned}
$$

for any $c \in E$. Which shows that $T^{n+1} x \rightarrow T z$ as $n \rightarrow \infty$. Now,

$$
\begin{aligned}
d_{G}(z, T z) & \leq d_{G}\left(T^{n+1} x, z\right)+d_{G}\left(T^{n+1} x, T z\right) \\
& \ll \frac{c}{2}+\frac{c}{2}=c,
\end{aligned}
$$

whenever $n>N$. Thus $d_{G}(T z, z) \ll \frac{c}{m}$, for all $m \geq 1$. So $\frac{c}{m}-d_{G}(T z, z) \in P$, for all $m \geq 1$. Since $\frac{c}{m} \rightarrow 0$ as $m \rightarrow \infty$ and $P$ is closed, therefore $-d_{G}(T z, z) \in P$ gives $d_{G}(T z, z)=0$ and hence $T z=z$.

Remark 3.2. If $X$ is not a symmetric $G$ - cone metric space, then as in above theorem, adding (3) and (4) we obtain the following

$$
d_{G}(T x, T y) \leq a d_{G}(x, y)+\frac{2(b+c+d)}{3} d_{G}(x, T x)+\frac{2(b+c+d)}{3} d_{G}(y, T y),
$$

for all $x, y \in X$. Here, $0 \leq a+\frac{2(b+c+d)}{3}+\frac{2(b+c+d)}{3}$ which may not be less than 1 . So above theorem gives no information.

Theorem 3.3. Let $X$ be a complete $G$ - cone metric space and $T: X \rightarrow X$ be a mapping satisfying one of (1) or (2). Then T has a unique fixed point.

Proof. Let $x_{0} \in X$. Define a sequence $\left\{x_{n}\right\}$ by $x_{n}=T^{n}\left(x_{0}\right)$. From (1) we have

$$
\begin{aligned}
G\left(x_{n}, x_{n+1}, x_{n+1}\right) \leq & a G\left(x_{n-1}, x_{n}, x_{n}\right)+b G\left(x_{n-1}, x_{n}, x_{n}\right) \\
& +(c+d) G\left(x_{n}, x_{n+1}, x_{n+1}\right) .
\end{aligned}
$$

It implies that

$$
G\left(x_{n}, x_{n+1}, x_{n+1}\right) \leq q G\left(x_{n-1}, x_{n}, x_{n}\right),
$$

where $q=\frac{a+b}{1-c-d}$. Obviously $0 \leq q<1$. Continue this process to obtain

$$
G\left(x_{n}, x_{n+1}, x_{n+1}\right) \leq q^{n} G\left(x_{0}, x_{1}, x_{2}\right) .
$$


Moreover for all $n, m \in N$ with $m>n$, we have

$$
\begin{aligned}
G\left(x_{n}, x_{m}, x_{m}\right) \leq & G\left(x_{n}, x_{n+1}, x_{n+1}\right)+G\left(x_{n+1}, x_{n+2}, x_{n+2}\right)+ \\
& +\ldots+G\left(x_{m-1}, x_{m}, x_{m}\right) \\
\leq & \left(q^{n}+q^{n+1}+\ldots+q^{m-1}\right) G\left(x_{0}, x_{1}, x_{1}\right) \\
\leq & \frac{q^{n}}{1-q} G\left(x_{0}, x_{1}, x_{1}\right) .
\end{aligned}
$$

Let $0 \ll c$ be given. Choose $\delta>0$ such that $c+N_{\delta}(0) \subseteq P$, where $N_{\delta}(0)=\{y \in$ $E:\|y\|<\delta\}$. Also, choose a natural number $N_{1}$ such that $\frac{q^{n}}{1-q} G\left(x_{0}, x_{1}, x_{1}\right) \in$ $N_{\delta}(0)$, for all $m \geq N_{1}$. Then, $\frac{q^{n}}{1-q} G\left(x_{0}, x_{1}, x_{1}\right) \ll c$, for all $m \geq N_{1}$. So we have $G\left(x_{n}, x_{m}, x_{m}\right) \ll c$, for all $m>n$. Thus $\left\{x_{n}\right\}$ is a Cauchy sequence, so there exist $u \in X$ such that $\left\{x_{n}\right\}$ converges to $u$. Now, from (1)

$$
G\left(x_{n}, T u, T u\right) \leq a G\left(x_{n-1}, u, u\right)+b G\left(x_{n-1}, x_{n}, x_{n}\right)+(c+d) G(u, T u, T u) .
$$

Taking limit $n \rightarrow \infty$, we get

$$
G(u, T u, T u) \leq(c+d) G(u, T u, T u),
$$

which implies that $T(u)=u$. To prove uniqueness, suppose that $u \neq v=T(v)$, then

$$
\begin{aligned}
G(u, v, v) & \leq a G(u, v, v)+b G(u, T u, T u)+(c+d) G(v, T v, T v) \\
& =a G(u, v, v),
\end{aligned}
$$

implies that $u=v$.

Theorem 3.4. Let $X$ be a complete $G$ - cone metric space, and $T: X \rightarrow X$ be a mapping satisfying one of the conditions

$$
\begin{aligned}
& G(T x, T y, T y) \\
\leq & a\{G(x, T y, T y)+G(y, T x, T x)\},
\end{aligned}
$$

or

$$
\begin{aligned}
& G(T x, T y, T y) \\
\leq & a\{G(x, x, T y)+G(y, y, T x)\},
\end{aligned}
$$

for all $x, y \in X$ where $a \in[0,1 / 2]$, then $T$ has a unique fixed point.

Proof. Suppose that $T$ satisfies condition (6), then for all $x, y \in X$

$$
G(T x, T y, T y) \leq a\{G(y, T x, T x)+G(x, T y, T y)\}
$$

and

$$
G(T y, T x, T x) \leq a\{G(x, T y, T y)+G(y, T x, T x)\}
$$

Now if $X$ is a symmetric $G$ - cone metric space, then above two inequalities give

$$
d_{G}(T x, T y) \leq a\left\{d_{G}(x, T y)+d_{G}(y, T x)\right\},
$$


for all $x, y \in X$. Since $0 \leq a<\frac{1}{2}$, therefore result follows from [9, theorem 2.7]. Now if $X$ is not a symmetric $G-$ cone metric space. Then adding (6) and (7) we obtain

$$
\begin{aligned}
d_{G}(T x, T y) & =G(T x, T y, T y)+G(T y, T x, T x) \\
& \leq 2 a\{G(y, T x, T x)+G(x, T y, T y)\} \\
& \leq \frac{4 a}{3}\left\{d_{G}(y, T x)+d_{G}(x, T y)\right\}
\end{aligned}
$$

for all $x, y \in X$. Here, contractivity factor $\frac{4 a}{3}$ may not be less than 1 . Therefor cone metric gives no information. In this case, let $x_{0} \in X$ and define a sequence $\left\{x_{n}\right\}$ by $x_{n}=T^{n} x_{0}$. So by (6)

$$
\begin{aligned}
G\left(x_{n}, x_{n+1}, x_{n+1}\right) & \leq a\left\{G\left(x_{n-1}, x_{n}, x_{n}\right)+G\left(x_{n}, x_{n}, x_{n}\right)\right\} \\
& =a G\left(x_{n-1}, x_{n+1}, x_{n+1}\right) .
\end{aligned}
$$

But

$$
G\left(x_{n-1}, x_{n+1}, x_{n+1}\right) \leq G\left(x_{n-1}, x_{n}, x_{n}\right)+G\left(x_{n}, x_{n+1}, x_{n+1}\right) .
$$

Thus we have

$$
G\left(x_{n}, x_{n+1}, x_{n+1}\right) \leq k G\left(x_{n-1}, x_{n}, x_{n}\right),
$$

where $k=\frac{a}{1-a}$, and $0 \leq k<1$. Continuing above process, we obtain

$$
G\left(x_{n}, x_{n+1}, x_{n+1}\right) \leq k^{n} G\left(x_{0}, x_{1}, x_{1}\right) .
$$

Now following similar arguments as those given in Theorem $4,\left\{x_{n}\right\}$ is a Cauchy sequence, so there exist $u \in X$ such that $\left\{x_{n}\right\}$ converges to $u$.

Now we show that $T u=u$. From (6)

$$
\begin{aligned}
& G\left(x_{n}, T u, T u\right) \\
\leq & a\left\{G\left(x_{n-1}, T u, T u\right)+G\left(u, x_{n}, x_{n}\right)\right\} .
\end{aligned}
$$

Which on taking limit $n \rightarrow \infty$ implies that

$$
G(u, T u, T u) \leq a G(u, T u, T u) .
$$

Thus $T u=u$. Suppose that $u \neq v=T v$, then

$$
G(u, v, v) \leq a\{G(u, v, v)+G(v, u, u)\},
$$

so

again, we have

$$
G(u, v, v) \leq k G(v, u, u)
$$

which implies that $u=v$.

$$
G(u, v, v) \leq k^{2} G(u, v, v)
$$

Example 3.5. Let $E=R^{3}, P=\left\{(x, y, z) \in R^{3} \mid x, y, z \geq 0\right\}$, and

$$
\begin{aligned}
X & =\left\{(x, 0,0) \in R^{3} \mid 0 \leq x \leq 1\right\} \cup \\
\{(0, x, 0) & \left.\in R^{3} \mid 0 \leq x \leq 1\right\} \cup\left\{(0,0, x) \in R^{3} \mid 0 \leq x \leq 1\right\} .
\end{aligned}
$$


Define mapping $G: X \times X \times X \rightarrow E$ by

$$
\begin{aligned}
& G((x, 0,0),(y, 0,0),(z, 0,0)) \\
= & \left(\frac{4}{3}(|x-y|+|y-z|),|x-y|+|y-z|,(|x-y|+|y-z|)\right), \\
& G((0, x, 0),(0, y, 0),(0, z, 0)) \\
= & \left((|x-y|+|y-z|), \frac{2}{3}(|x-y|+|y-z|),(|x-y|+|y-z|)\right), \\
& G((0,0, x),(0,0, y),(0,0, z)) \\
= & \left((|x-y|+|y-z|),|x-y|+|y-z|, \frac{1}{3}(|x-y|+|y-z|)\right)
\end{aligned}
$$

and

$$
\begin{aligned}
G((x, 0,0),(0, y, 0),(0,0, z)) & =G((0,0, z),(0, y, 0),(x, 0,0))= \\
\ldots \ldots & =\left(\frac{4}{3} x+y+z, x+\frac{2}{3}+z, x+y+\frac{1}{3} z\right) .
\end{aligned}
$$

Then $X$ is a Complete $G$ - cone metric space. Let $T: X \rightarrow X$

$$
\begin{aligned}
T & =(x, 0,0)=(0, x, 0), T(0, x, 0)=\left(0,0, \frac{1}{3} x\right), \\
\text { and } T(0,0, x) & =\left(\frac{2}{3} x, 0,0\right) .
\end{aligned}
$$

Then $T$ satisfies the contractive condition given in Theorem 5 with constant $a=\frac{3}{4} \in[0,1)$. Note that $T$ has a unique fixed point $(0,0,0) \in X$.

\section{REFERENCES}

[1] M. Abbas and G. Jungck, Common fixed point results for noncommuting mappings without continuity in cone metric spaces, J. Math. Anal. Appl., 341(2008), 416-420. 1]

[2] M. Abbas and B. E. Rhoades, Fixed and periodic point results in cone metric spaces, Appl. Math. Letter, (2008), doi:10.1016/j.akl.2008.07.001. 1

[3] B. C. Dhage, Generalized metric space and mapping with fixed point, Bull. Calcutta. Math. Soc., 84 (1992), 329-336. 1

[4] L.-G. Haung and X. Zhang, Cone metric spaces and fixed point theorems of contractive mappings, J. Math. Anal. Appl., 332 (2007), 1468-1476. 1, 2

[5] R. Kannan, Some results on fixed points, Bull. Calcutta Math. Soc. 60 (1968), 71-76. 1

[6] Z. Mustafa, O. Hamed and F. Awawdeh, Some fixed point theorem for mappings on complete $G$ - metric spaces, Fixed Point Theory and Applications, Vol. 2008 (2008), Article ID 189870, 12 pages. 1

[7] Z. Mustafa and B. Sims, Some remarks concerning D-metric spaces. Proceedings of the Int. Conference on Fixed Point Theory and Applications, Valencia (Spain), July (2003). 2

[8] Z. Mustafa and B. Sims, A new approach to Generalized Metric Spaces. J. Nonlinear and Convex Anal., 7(2) (2006), 289-297. 1, 2

[9] S. Rezapour and R. Hamlbarani, Some notes on the paper " Cone metric spaces and fixed point theorems of contractive mappings", J. Math. Anal. Appl., 345 (2008), 719-724. 
$1,2,2,3,3$

Department of Mathematics and Centre for Advanced Studies in Mathematics, Lahore University of Management Sciences, Lahore, Pakistan.

E-mail address: ibeg@lums.edu.pk 